\title{
La represión inquisitorial: los hechos de Arjona y la cárcel de Jaén en la época de Felipe el Hermoso
}

\author{
Pedro A. Porras Arboledas *
}

La llegada de Felipe I a España para tomar posesión del Reino junto a su esposa Juana supondria un paréntesis de esperanza para los perseguidos del Santo Oficio, quienes pensaban que, tras varias décadas de represión cruenta, podrian encontrar un poco de paz en su existencia o, al menos, disfrutar de unas minimas garantias procesales en los sumarios abiertos. Fruto de esta esperanza es el documento que transcribimos y glosamos en este trabajo '; se trata de un memorial de quejas - ya conocido y mencionado en su día por Heriry C. Lea ${ }^{2}$ - presentado por los presos de la Inquisición de Jaén, en el que se relatan al nuevo monarca el sinfin de vejaciones y malos tratos que les eran propinados por los inquisidores gienenses, seguidores de los métodos del cruel Lucero, durante su estancia en la cárcel (insalubridad, hambre, tormentos, indefensión, expolio de sus bienes, extracción violenta de confesiones, delaciones falsas, etc.). Sin embargo, lo más abominable del relato presentado son los hechos acaecidos en la Villa Calatrava de Arjona - donde antaño habia existido una importante juderia, al igual que en Jaén, Úbeda, Baeza y Andújar ${ }^{3}$-; alli se habian desplazado los inquisidores, primero,

Profesor Titular de Historia del Derecho. Universidad Complutense de Madrid.

Archivo General de Simancas, Patronato Real, 28-38. El documento debe fecharse dentro de los cinco meses que Felipe estuvo en la Penínsuia, entre su desembarco en La Coruña (26 abril 1506) y su fallecimiento (25 de septiembre).

2 Historia de la Inquisición española. Madrid 1983, I, págs. 231-234.

"No deja de llamar la atención que, a pesar de constatarse este hecho fácilmente, estas comunidades hebreas en tierras gieneneses sean unas desconocidas en la historiografia actual; véase por ejemplo el reciente trabajo de Bel Bravo, M. A. (Los Reyes Católicos y los judios andaluces (1474-1492). Granada 1989), donde no aparecen estas comunidades conversas, bautizadas con toda probabilidad durante el progrom de 1391 .

Por mi parte, tengo en prensa en la revista Inquisitio mi trabajo "Inquisición, comercio y banca: la comunidad judeoconversa de Jaén (1475-1540)". 
a registrar a todos los conversos, mediante delaciones en masa, y más tarde a capturarlos de modo inmisericorde. Se trata, en suma, de un relato del máximo interés que merece ver la luz integramente, convenientemente glosado.

Este notable documento tiene, pues, dos grandes apartados, uno primero dedicado a denunciar los agravios que se les propinaban a los presos de la Inquisición en la cárcel de Jaén y otro, donde se narran con detalle los atropellos sufridos por los conversos de Arjona.

\section{LA SITUACIÓN EN LA CÁRCEL INQUISITORIAL GIENENSE}

El momento en el que se produce este memorial de agravios no podia ser peor para estos conversos: Jaén y su Reino se hallaban sumidos en una época de malas cosechas y de pestilencia, lo que llevó a muchos mercaderes conversos, por una parte, a pedir la rebaja en los arrendamientos de rentas reales y concejiles, y, por otra, a redactar sus últimas voluntades ${ }^{4}$. Así mismo, fueron unos años dificiles para la comunidad conversa a causa de las persecuciones desencadenadas por el Santo Oficio contra los mercaderes más adinerados, como ellos mismos denunciaron a la Reina el 18 de septiembre de 1507.

En esa fecha se reunieron en la parroquia de Santa Cruz _-una de las dos antiguas sinagogas gienenses- los mercaderes Antón Rodriguez de Amores, Diego de Córdoba, Juan de Jaén Marruecos, Lope Fernández de Chinchilla -condenado poco después, junto con su mujer, por el Santo Oficio- Garci Gutiérrez, Juan Álvarez y Diego de Priego, los cuales, por cuanto ellos eran arrendatarios de las alcabalas de Jaén en ese año, en las cuales

ay mucha pérdida e quiebra a cabsa de la grant pestilençia e mortandad que en la dicha Cibdat ha avydo, como con la grand esterilidad non se cogió ningúnd pan ni las olivas ni viñas no llevan fruto ni esquilmo alguno, ni lo tienen, e asy mismo por la Santa Ynquisiçión, que han seydo e están presos muchos vezinos de la dicha Çibdad, cabdalosos mercaderes tratantes, a cabsa de lo qual nos conviene suplicar a la Reyna, nuestra señora...

- Sobre todas estas cuestiones, véase mi trabajo antes citado, elaborado, fundamentalmente, a base de las anotaciones de los protocolos notariales. 
Lo que suplicaban a la Reina era que se les hiciera

suelta e quita e descuento del grand daño e pérdida e quiebra que por las dichas cabsas nos ha venido e recresçido a las dichas rentas e a cada una dellas ${ }^{5}$.

Un año antes, cuando se redacta la denuncia que publicamos, la cárcel inquisitorial albergaba alrededor de 200 presos, en su mayoría procedentes tanto de Jaén como de Arjona. La iniciativa en la presentación de la mencionada súplica corrió a cargo de los familiares de los encarcelados, quienes dirigieron al recién desembarcado Rey un conjunto de 20 capitulos, conteniendo quejas contra la actuación inquisitorial, que se pueden clasificar en seis grandes apartados.

\section{Quejas de carácter general}

La primera y más emblemática de las mismas aseguraba que los inquisidores eran partidarios de las opiniones del inquisidor cordobés Lucero, con quien mantenian frecuentes relaciones epistolares, el cual les facilitaba delatores falsos [ $\$$ 1]; tal era el estado de terror infundido en la población que nadie se atrevia a quejarse de estas actividades por temor a las represalias de los inquisidores, como habia sucedido en Córdoba, donde los que habian osado hacerlo estaban presos o muertos [ $\$ 17$ ].

En general, se decia que actuaban por la noche, prendiendo a marido y mujer, expulsando a la calle a hijos y criados con lo puesto, secuestrando los bienes por si mismos y repartiéndoselos entre ellos [\$18]. La actuación arbitraria la ejemplarizaron con el caso del secretario Garcia de Jaén, escribano del crimen de esa Ciudad, quien había acusado y exonerado por los inquisidores y, a pesar de ello, le privaron del oficio para entregarlo al alcaide Ginés de Gorbalán, hombre del cortesano Antonio de Fonseca [ $\left[\begin{array}{ll}\S & 19\end{array}\right]$.

\section{Quejas contra el sistema carcelario}

Las cárceles inquisitoriales, según esta denuncia, eran pequeñas y oscuras, con suciedades y alimañas, húmedas, frias en invierno y calurosas

\footnotetext{
${ }^{5}$ Firmaron todos los indicados, excepto Anton Rodriguez, que era analfabeto (Archivo Histórico Provincial de Jaén, protocolo 11, fol. 457). Diego de Córdoba, de profesión joyero, habia dictado testamento el 19 de mayo de ese año, en plena epidemia de peste, aunque sobrevivió a la misma (ibidem, fol. $378 \mathrm{r}-379 \mathrm{v}$ )
} 
en verano, donde pasaban sed y hambre, ya que recibian una libreta de pan diaria por persona, es decir, 16 onzas para dos comidas. Pero lo peor era el maltrato recibido de los carceleros, «que más son las dichas cárçeles que tenemos tormentos que no cárçeles ni guarda»[ $\$ 4]$.

\section{Quejas contra las medidas de seguridad}

Se quejaban de que, en cierta ocasión, les habian prohibido la salida de la ciudad a los conversos, so pena de ser apresados por cualquiera, y aunque luego revocaron la orden, algunos malsines capturaron a algunos fuera de las murallas, yendo a sus negocios, y los encarcelaron, permaneciendo en esa situación más de un año sin acusación alguna [§ 9$]$.

\section{Quejas de carácter éconómico}

Era éste uno de los aspectos en que la indefensión se manifestaba de modo más crudo, advirtiéndose el espiritu de lucro con el que actuaban inquisidores y subalternos. Vendian los bienes de los presos sin haber sido procesados, gastaban el dinero en metálico con que se encontraban y a los que salian libres les obligaban a firmarles cartas de finiquito por los bienes que les habian dilapidado durante el encarcelamiento [\$ 6].

También se encargaban de cobrar las deudas de que los presos eran acreedores, nombrando costosos factores y recaudadores, en perjuicio de la hacienda real, pues caso de ser condenados el fisco no hallaba bienes. En resumidas cuentas, actuaban como si no tuvieran que dar cuenta a nadie [ $\$ 7$ ], provocando la huida del reino de muchos conversos que se marchaban para evitarse todas estas vejaciones ${ }^{6}$ [ $\left.\$ 15\right]$.

\section{Quejas por la designación de oficiales}

Por una vez las quejas se individualizan en personas concretas: probablemente, el más odiado de los subalternos inquisitoriales fue el notario Antonio de Bárcena, al que acusaban de aumentar las deposiciones

\footnotetext{
${ }^{6}$ Un ejemplo de esto lo tenemos documentado en Málaga, en 1508, donde un trapero gienense, huido de la Inquisición, era acreedor de Abahén Zerchel, escudero de Ali Barrax, por $12.600 \mathrm{mrs}$. (LOPEZ DE COCA, J. E., "Esclavos, alfaqueques y mercaderes en la frontera del mar de Alborán (1490-1516)», Hispania, CXXXIX, 1978, pág. 300).
} 
de los testigos de cargo, de dar tormento, de preguntar y repreguntar como si fuese juez, de injuriar a los acusados y de tomar declaraciones en ausencia de los inquisidores.

Se decia que habia apresado a 15 ó 20 personas en Arjona, trayéndolos alegremente hasta Jaén; en la misma Arjona-donde, como vamos a ver, tuvo una actuación más que destacada- habia tomado a una joven de 15 años, a la que desnudó y encerró, propinándole 100 azotes y amenazándola de muerte, para que testificase contra su propia madre, lo que acabó por hacer. Se quejaban de que los inquisidores les imponian notarios corruptos, rechazando a los honrados [\$ 10].

Igualmente fueron objeto de sus odios dos ciérigos gienenses, uno de ellos el prior de San Bartolomé, Martín Sánchez, a los que consideraba enemigos declarados; éstos habían sido designados para examinar testigos. Del mencionado prior se alegaba que se hizo nombrar guarda y obrero de la cárcel, en donde se encargó de cerrar los vanos de la misma, tomando, además, para si los bienes de los presos. Se habia hecho amigo de Juan de Aguilera, despensero de la cárcel, con quien repartía las ganancias que obtenia disminuyendo las comidas servidas a los presos [ $\$ 111]$.

En términos generales, denunciaban la designación de un excesivo número de oficiales (despenseros, alguaciles ejecutores y notarios especiales), que con el cobro de sus salarios dilapidaban las fortunas de los encarcelados [\$20].

\section{Quejas procesales ${ }^{7}$}

Sin embargo, las quejas más abundantes -alcanzan la mitad del total- eran las de carácter procesal, acusando a los oficiales del Santo Oficio de dejarles en la indefensión más absoluta.

Dicha indefensión se producia por diversas vias: incomunicando a los acusados con sus familiares e impidiéndoles escoger libremente letrados y procuradores - hasta el extremo de que los inquisidores tomaban juramento a los letrados que adjudicaban a los presos de que no comunicarian los procesos con los parientes de éstos [\$13]-; dichos letrados, además, eran aleccionados por los inquisidores, percibiendo, en compensación altos honorarios (3.000 mrs./preso) [\$5].

\footnotetext{
Sobre El proceso de la Inquisición española ha escrito un extenso y documentado trabajo mi compañero Bruno Aguilera Barchet, de inminente publicación.
} 
Así mismo, los fiscales ampliaban notablemente los escritos de acusación, no especificándose en los mismos datos como la fecha o el objeto de la acusación ni el lugar de comisión del delito, ni se hacia publicación de testigos, con lo que impedian la presentación de excepciones o la recusación de testigos [ $\$ 8$ ]. Precisamente, lo relativo a la manipulación de los testigos ocupa el centro de estas denuncias: adoctrinaban a los mismos, escogidos entre los esclavos y mozos de servicio de los presos, halagándoles o amenazándoles y asegurándoles el mantenimiento del secreto de sus declaraciones [ $\$ 2$ y 16 ]. Los jueces competentes no examinaban a los testigos [ $\$ 1]$, por lo que era práctica corriente la presentación de testigos falsos, como el caso flagrante de Diego de Algecira, con la funesta consecuencia de que la persecución se centraba en los linajes más importantes [\$1].

En su prepotencia, los inquisidores no daban parte de los procesos, como estaban obligados, a los prelados [\$12], ni mucho menos a los parientes de los procesados, antes al contrario maltrataban a los que se interesaban por los mismos [ $\$ 14$ ]. También se denunciaba la utilización de tormentos de agua, de garrotes a manos y brazos, de garrucha o de fuego, habiéndose dado el caso de un condenado que fue llevado al quemadero sentado por tener los pies quemados «hasta el çelebrón» [\$ 16]. En suma, se quejaban de las detenciones masivas, llevadas a cabo con la colaboración de malsines, tanto en Torredonjimeno [\$3] como en Arjona.

\section{EL PROGROM DE ARJONA}

Aunque desconocemos los detalles de lo sucedido en la villa calatrava de Torredonjimeno, no creo que fueran muy distintos de los hechos acaecidos en Arjona, que nos son relatados con detenimiento en la mencionada carta de denuncia. La relación de estos hechos se desarrolla cronológicamente a través de catorce puntos, en los que se aprecia una progresión provocada por vecinos avariciosos e inquisidores para crear un climax determinado, cuyo fin no fue otro que el apresamiento de la comunidad conversa urgavonense.

Se achacaba a Álvaro de Escalera y otros vecinos de esa localidad calatrava el haber llamado a los inquisidores, ofreciéndoles "una mina de oro" y ofreciéndose para denunciar, con la finalidad de comprar las heredades de conversos a bajo precio [ $\$ 1$ ]; unidos a un inquisidor y al mencionado notario Bárcena, fueron casa por casa amonestando a los vecinos 
para que denunciasen a los conversos [\$2]; también reunieron a todos en una iglesia para leerles una carta de edicto escandalosa [ $\$ 3$ ]. Singularmente, Ilamaron a los esclavos exhortándoles a denunciar a sus amos y ofreciéndoles la libertad a cambio [\$ 4].

Como ello no debió ser suficiente, trajeron a predicar a un dominico para alborotar al pueblo contra los conversos; dicha predicación se repitió varios dias, en la que se denunciaba la superficial conversión de los mismos, invitando a los cristianos viejos a presentar declaraciones falsas, en especial, que hacian reuniones, cuando en realidad sólo lo hacian con ocasión de bodas o convites [\$5]. Tras la predicación, Bárcena, acompañado de varios malsines y un pregonero, cabalgaba por la villa, pregonando que todos fueran a presentar denuncias. También empadronó a toda la villa, multando a los que no habian acudido a denunciar [ $\$ 6]$.

El propio Bárcena deambulaba por las calles, invitando a las mujeres a denunciar a los conversos, pues les decia que era cierto que eran herejes, que no tuviesen cuidado, ya que nadie sabria quién les habia denunciado [§7]. Así mismo, sin autorización del inquisidor, Bárcena tomaba deposiciones de testigos, enviaba cédulas requiriendo fuesen a denunciar y amenazaba con llevar a la cárcel de Jaén a quienes no to hiciesen [\$8]; también amenazaba a los que protestaban por lo escrito en la diligencia de ratificación de sus deciaraciones; concretamente, Luis de Vilches cantarero, criado de Bárcena, habia testificado varias veces tras cambiarse de vestidos y de nombre [\$9].

Tras aterrorizar a la población, los inquisidores partieron, dejando defraudados a los malsines; uno de los principales, Lope Gómez, se quejaría de que había perdido dinero en tales circunstancias [ $\$ 10$ ].

Pero la tranquilidad no volvería para estos conversos: tres meses más tarde comparecieron en la villa de noche un alguacil, un receptor y varios notarios, diciendo a alcaldes y regidores que venian a prender herejes, que reuniesen gente secretamente, guardando puertas, caños y portillos para evitar huidas. Todos esos lugares deberian ser tomados por gente armada. Acto seguido comenzaron a prender a los conversos casa por casa, echando a los hijos y criados a la calle y rapiñando la comida de las casas. Duró el apresamiento desde la mañana del domingo hasta la noche del lunes, prendiéndose a 40 personas. Pasada una semana, entraron en las casas precintadas, llevándose todo lo de valor [ $\$ 11]$.

La depredación no hizo sino empezar con ello, ya que se repartieron a los esclavos entre malsines y funcionarios inquisitoriales, dejando abandonados a los hijos de los presos; también pidieron a los inquisidores les adjudicasen las cantidades para el mantenimiento de los esclavos, y como resultado de ello algunos esclavos murieron de hambre [ $\S 12]$. Asi 
mismo subastaron los bienes de los presos por debajo de su valor, adjudicándolos arbitrariamente, y cobrando derechos de los adjudicatarios después de haber pregonado que eran horros [ $\$ 13]$. En fin, se denunciaba que los presos de Arjona habian sido detenidos sin información previa, por obra del notario Bárcena [§ 14].

\section{CONCLUSIÓN: PETICIONES DE LOS FAMILIARES DE LOS PRESOS}

Ante tan oscuro panorama, el procurador de los familiares de los encarcelados - un letrado desconocido, que apenas aparece en el documento; tan sólo al final hay una referencia en primera persona, cuando se queja del arzobispo de Sevilla- no pudo por menos que pedir que en todo se actuase conforme a Derecho, denunciando lo que, en buena medida, no era sino el procedimiento inquisitorial habitual en aquellos momentos.

Las peticiones concretas eran las siguientes:

1. ${ }^{a}$ que se averiguase la verdad por personas de conciencia.

2. que les permitiesen elegir libremente sus letrados y procuradores.

3. ${ }^{a}$ que se les oyese de nuevo.

4. ${ }^{\text {a }}$ que se comunicasen sus procesos a sus familiares.

5. que el obispo de Jaén, Alonso Suárez de la Fuente del Sauce, entendiese en sus casos, como Inquisidor General que era.

6. ${ }^{a} \quad$ que se aceptase la recusación contra el arzobispo de Sevilla por enemigo notorio, ya que habia desoido una orden real, ordenándole comunicar los procesos a los familiares de los encausados.

No se trataba, pues, de peticiones excesivas, tan sólo se pretendia que se les aplicasen las normas habituales en el procedimiento penal ordinario y que se actuase en sus casos con buena fe, cosa que esperaban conseguir del nuevo monarca, tan poco afecto a la Inquisición. El prematuro fallecimiento del mismo dio al traste con las esperanzas que estos conversos habian depositado en su gestión; la vuelta de Fernando el Católico al poder supondría el mantenimiento del statu quo. 


\section{[1506]}

Los presos de la cárcel de la Inquisición de Jaén dirigen un memorial de quejas a don Felipe el Hermoso, exponiéndole las vejaciones a que se les sometia y denunciándole los métodos utilizados por los inquisidores, seguidores de la opinión de Lucero, en especial durante los hechos ocurridos en la villa de Arjona.

Archivo General de Simancas, Patronato Real, legajo $28, n .^{\circ} 38$. Original.

Muy alto e muy poderoso señor:

Los presos de la Ynquisiçión de la Çibdad de Jahén e su partido dezimos que resçebimos e avemos resçebido de los de los ynquisidores del dicho obispado de Jaén e su partido, demás de los agravios de los vezinos de la vila de Arjona, qu'es del Maestradgo de Calatrava, los agravios syguientes:

[1] Lo uno porque los ynquisidores del dicho obispado de Jahén han seguido e syguen la opinión de Luzero, ynquisidor de Córdova, el qual ha sido e es el mayor enemigo que este linaje tiene y el más odioso juez, procurando de matar e estruyr a todos los desta generaçión por todas las vias e maneras e formas que puede y ha podido, viéndose con él e carteándose e platicando e usando entre ellos el daño e perjuyzio deste linaje, e procurando de aver testigos de Córdova para destruyr e matar todos los del obispado de Jahén falsos e contra la verdad diziendo e levantando testimonios contra esta generaçión que nunca fue ni pasó ni se pensó, e pruévase esto quie hizo a Diego de Algezira testificase a muchos vezinos de Jahén e de su obispado, que ha çinco años qu'el dicho Diego de Algezira está preso en la cárçel de Córdova, para que testificase contra quien Luzero quisyere, y ha testificado contra quien no vido ni conosçió ni partiçipó. Y esto pareçerá por los proçesos de los condenados que con testigos falsos fueron quemados y tomados sus bienes e sus hijos dellos quedan perdidos muriendo de hanbre e padesçen otras desonrras e ynfamias que por razón de aquello se les ha recresçido. Créese e presúmese que por el dicho e depusyçión del dicho Diego de Algezira los ynquisidores del dicho obispado de Jahén han prendido muchas personas varones e mugeres, los más ricos e onrrados de la Çibdad e su obispado, e asy ha hecho a todos los deste linaje del Reyno, seyendo creydo el dicho Diego de Algezira por formas e por maneras por el dicho Luzero, e ello seyendo el dicho Diego de Algezira el peor onbre e de más mala fama e condiçión e conçiençia que nasçió en el mundo. E lo que peor es que los dichos ynquisidores del obispado de Jahén no esaminaron por sus personas el dicho del dicho Diego de Algezira, que como buenos juezes heran obligados a to hazer e saber si dezia falsedad o verdad, mayormente seyendo el dicho Diego de Algezira borracho e tahur e çerçenador de moneda e falsario, perjuro, reconçiliado e loco e amenguado.

[2] Otrosí, que los dichos ynquisidores del dicho obispado de Jahén e su partido an procurado de aver otros testigos falsos, que dixeron to que nunca vieron ni fue ni pasó contra este linaje, prendiendo e encarçelando esclavos e esclavas e moços e moças de serviçio de personas desta generaçión, e teniéndolos presos e en mucha fatyga e escuridad, e asy mismo a otras personas no soltándolas de la cárçel e faziéndoles muchos halagos e promesas para que falsamente dixesen sus dichos contra nosotros e contra otras personas deste linaje, e quando por este camino no podian le hazian muchas amenazas fasta tanto que dixeron lo que los dichos ynquisidores quisieron.

[3] Otrosy, que manifestando e mostrando los dichos ynquisidores el odio e enemistad que tienen a este linaje, prendiendo como han prendido a muchas personas de la villa de 
Torredonximeno, lugar del dicho Maestradgo de Calatrava, por dicho de un tornadizo cativo que fue judio, que es aguador, el más menguado e loco e abilitado del mundo, e dicho su dicho a traydo a ello por tres reales que le dixeron malsines e enemigos deste linaje, vezinos de la dicha villa de Torredonximeno.

[4] Otrosy, que los dichos ynquisidores han tenido e tienen los presos deste linaje en mucha fatiga e oprisyón, teniéndoles en cárçeles pequeñas e escuras e en grandes prisyones con dos partes de puertas que no veen claridad ninguna, llenas de muchas suçiedades, ratones, culebras, gosanos e otras suçiedades, e otras dellas muy húmidas, pasando en ellas mucho frío en los ynviernos e mucho calor en los veranos e mucha sed e hanbre, no dándoles syno una libreta de pan a cada uno, que son diez e seys onças para dos comidas cada dia, seyendo aflegidos e bituperados con mucha soberbia de los carçeleros e gentes que guardan la cárçel. De manera que avemos resçebido e resçebimos en la dicha cárçel grandes tormentos e fatigas, que más son las dichas cárçeles que tenemos tormentos que no cárçeles ni guarda, sabiendo los dichos ynquisidores que aunque quedásemos sueltos no nos aviamos de yr.

[5] Otrosi, que los dichos ynquisidores nos an quitado a todos los presos toda la defensa de nuestro derecho, defendiéndonos que no veamos ni partiçipemos nuestra justiçia con nuestros hijos ni los hijos con los padres ni con otra persona alguna, ni tomemos los letrados ni procuradores que queremos e pedimos e avemos pedido, salvo los letrados que los dichos ynquisidores quieren e les ha plazido, e puestos de su mano, e los dichos letrados no han hecho ni hazen ni dizen ni alegan más por nosotros de lo que les es mandado por los dichos ynquisidores, e aunque avemos pedido aconpañados, no nos dan ni han querido dar el letrado que avemos pedido, porque estos letrados puestos por la mano de los dicho ynquisidores son mucho sus amigos asalariados por ellos e sus muy mandados como subjetos e son enemigos de nosotros, deseando que oviese muchos más por el salario que tienen e llevan de nuestros bienes, que llevan de cada uno tres mill mrs., e por dosyentos presos que puede aver, poco más o menos, llevan seysçientas mill mrs., y no quieren ni osan los dichos letrados poner sospecha en los dichos ynquisidores quando es nesçesario ni ynterponer apelaçión

[6] Otrosy, que los dichos ynquisidores han fecho vender muchos bienes nuestros syn ser nosotros condenados, e todos los mrs. de los dichos bienes vendidos e todos los mrs. que nos fueron hallados en dineros, todos los han mandado tomar e gastar en lo que han querido e les ha plasydo, e aun sy alguno ha salido libre o lo han soltado, le han fecho otorgar fyniquito los dichos ynquisidores de lo que malamente le han fecho gastar de sus bienes o le han echado a perder.

[7] Otrosy, que los dichos ynquisydores han mandado cobrar las debdas devidas a nosotros, poniendo para ellos muchos fatores e recabdadores en daño e perjuysio de nuestras hasyendas por salario que les dan de los dichos nuestros bienes, por dar de comer a quien quieren, hasyendo graçia de lo que no pueden ni es de su ofiçio e aun en perjuysio del fisco real, porque sy el tal preso fuere condenado el reçebtor en nonbre del fisco lo cobrara. Asy que en presonas e bienes usan los dichos ynquisydores tan absolutamente con sy dello no oviesen de dar cuenta a Dios, nuestro señor, ni a V.A. qu'está en lugar de Dios en la tierra en estos sus Reynos e señorios.

[8] Otrosy, que los dichos ynquisydores no han querido ni quieren mandar al fiscal que nos acusa, aunque le es pedido por nosotros que ponga en su acusaçión o acusaçiones dia de mes e de año e nonbrando partiçipe e lugar de delito, pues los derechos asy lo quieren para poner sy el acusado quisyere exepçión yndireta para que çesen o se anulen algunos dichos de testigos falsos. Ni han querido haser publicaçión de los nonbres de los testigos con los dichos para que digamos e aleguemos de la defensa de nuestra justiçia, pues que 
el derecho asy lo quiere, mayormente por ser como somos gente llana e jaxa e de poco valor, y no se espera peligro al fiscal e a los testigos, mayormente en tienpo de tanta justiçia como V.A. tiene en estos sus Reynos. $Y$ demás que sy contra alguno es avida ynformaçión falsa de testigos sumaria, que disen de una cosa o dos quando el fiscal pone la acusación pone de çien cosas, qu'es contra derecho y es propio caluniador el que tal acusaçión pone. porque caluniador acusador es el que de falsos delitos sabidamente acusa.

[9] Otrosy, que los dichos ynquisydores hisyeron pregonar públicamente que ninguna persona deste linaje saliese fuera de los adarves desta Cibdad syn su liçençia en dia señalado de Santa Maria de Agosto, so pena que fuesen presos por qualesquier persona e traydos a la cárçel de la Ynquisiçión e otras penas pecuniales, no aviendo cabsa ni ynformaçión ni ocasión para ello, e puesto que lo mandaron revocar veyendo su herror, después de algunas personas deste linaje que salieron a negoçiar sus hasyendas o a lo que les cunplia fueron traydos presos por malsynes e otras malas personas a la cárçel, en la qual los han tenido e tienen pasando el dicho tormento un año e más e menos e algunos han soltado e a otros tienen presos syn les ver un año e más e menos e syn les aver puesto demanda, en gran perjuysio de sus hasyendas e personas, e los que han soltado les han hecho otorgar finequito de las pérdidas que les han fecho perder de sus hasyendas.

[10] Otrosy, que los dichos ynquisidores han procurado de thener en el dicho ofiçio los notarios que les ha plasydo e han tenido manera que saliesen del dicho ofiçio los notarios de buena conçiencia e fieles en su ofiçio, porque no querian escrevir salvo la verdad. Espeçialmente, han thenido en el ofiçio un notario que se Ilama Antonio de Bárzena, el qual es muy enemigo deste linaje e ha procurado e procura de nos estruir e matar, asy creçiendo en los dichos e depusyçiones de los testigos que contra nosotros deponen falsamente, como dando el propio tormento a los presos e apretándolos e repreguntándolos más que sy él fuese el propio juez y el juez proçediese como enemigo, procurando por todas las vias e maneras que ha podido e puede de haser toda la contrariedad a este linaje, ynjuriándolos en los tormentos disyéndoles "perros erejes judios, desyd que soys erejes". E asy mismo el dicho Antonio de Bárzena notario truxo a la Cibdad de Jahén de la villa de Arjona de una vez quinse o veynte presos deste linaje por la plaça, veniendo él tras ellos ençima de un cavallo en sayo con ramos en la mano con mucha alegría y plaser, e lo que más grave e peor es que seyendo el dicho Bárzena muy odioso e henemigo deste linaje, e por sy solo tomava e tomó los dichos e depusyçiones de los testigos en el dicho obispado de Jahén e su partido syn estar presente a ello ninguno de los ynquysydores, e tomó en la villa de Arjona una moça de quinse años e la desnudó en un palaçio e çerró la puerta por de dentro e le dio más de çient açotes, en tal manera que la oviese de matar porque dixese contra su madre e contra otros falso testimonio, e con este tormento dixo todo lo qu'él quiso.

[11] Otrosy, que los dichos ynquisydores escojeron en la C̣ibdad de Jahén dos personas clérigos henemigos deste linaje, el uno es Martin Sánchez, prior de San Bartolomé, para que oviesen de estar en la examinaçión de los testigos, el qual se ha mostrado tan henemigo deste linaje que por todas las vias e maneras que ha podido to ha destruydo e echado a perder, e se ha hecho guarda de la cárçel e obrero della, procurando de cerrar y apretar los presos e todos los agujeros e ventanas e lunbreras de la cárçel, e aun ha tomado muchos bienes de los presos que se avian de poner en poder de los secrestadores por los ynpider e tomar para sy, y hasyendose compañero de Juan de Aguilera, despensero de los presos, para partyr entrellos amos a dos la ganançia adelgazando las comidas para que ellos oviesen mayor provecho.

[12] Otrosy, que los dichos ynquisydores, como sy ellos fuesen el Sumo Pontifiçe, se han apartado de conferir e comunicar y dar parte al prelado e a su provisor de las cosas e proçesos del dicho ofiçio que de derecho av de entender en todo ello, asy como hordinario por les quitar a los presos en toda su defensa, e hazer ellos solos el mal y daño que pudiesen, como lo han fecho, y quitandonos el comunicar de nuestros pleitos con los letrados que pedimos e con nuestros parientes e ha proçedido contra nosotros como contra persona ynauditas. 
[13] Otrosy, que los dichos ynquisydores a los letrados que nos han dado contra nuestra voluntad les tomavan e tomaron juramento que no partiçipasen nuestros pleitos e acusaçiones e abtos de los dichos proçesos con nuestros hijos, ni muger ni parientes, que no saben sy somos muertos ni bivos, donde es ynposible o grand maravilla, aunque tengamos mucha justiçia e rasón, poder salir al cabo que aquélla se sepa o esclaresca, mayormente no dándonos publicaçión de los testigos con sus çircunstançias.

[14] Otrosy, que porque algunas personas han procurado de entender en los casos de sus padres o hijos o parientes presos, ha seydo maltratados e ynjuriados e presos por los dichos ynquisydores e sacados a la vergüença y açotados a bos de pregonero, y se han hallado muchos testigos falsos contra este linaje y no se ha punido ni castigado, antes los han favoresçido, atrayéndolos a que cresçiesen sus dichos.

[15] Otrosy, que algunas personas deste linaje, veyendo la grande henemiga que los dichos ynquisydores les thenian, viendo cómo proçedian exarrutamente, viendo el grand perjuysio e daño e prisyones de hecho que los dichos ynquisydores hasyan e han fecho por thenor de no ser presos de hecho, syn aver fecho cosa alguna porque deviesen resçebir fatyga ni prisyón, se han ydo e absentado destos Reynos, los quales, sy oviese ynquisydores syn sospecha que la jusțiçia quisyesen guardar, luego se bolverian a la dicha Çibdad de Jahén e a su obispado.

[16] Otrosy, que los dichos ynquisydores han fecho dar a los presos muy grand e terribles tormentos, asy de agua como de garrotes a las manos e braços, como de carrucha como de fuego, e se provará aver dado a preso e presos todos los dichos tormentos, e asy pareció aver sacado a quemar algúnd preso con los pies todos asados e quemados hasta el çelebrón, con los tormentos que le dieron, llevándolo en una sylla como muerto a quemar, porque no podia yr con sus pies, y créese que el tal preso no quiso confesar la mentira e falsedad de que hera acusado, no enbargante que le fueron dados los dichos tormentos, lo hisyeron quemar a él e a su muger, e después por adobar el dicho proçeso prendieron dos esclavas que heran de los dichos marido e muger, e las tovieron presas çierto tienpo después de quemados los dichos sus señores para que dixesen contra ellos falsamente, sy no que no serian horros.

[17] Otrosy, que muchas personas deste linaje se ovieran ydo a quexar de los dichos agravios e ynjustiçias, salvo por el themor de los dichos ynquisydores, porque veyan e sabian, segúnd el odio e henemistad que tenia contra este linaje, que no avian de ser oydos, antes themian que avian de ser presos e muertos, como se hiso a los que se fueron a quexar de Córdova.

[18] Otrosy, que los dichos ynquisydores mandaron prender a marido e muger juntamente de noche y echaron a los hijos e creados en la calle e çerraron las puertas de los tales presos, e secrestaron los bienes, asy de noche como de día por sy solos, e tomavan e repartyan entre sy lo mejor, asy de vestiduras como joyas de oro e plata e moneda e trayan con ellos honbres de mal bivyr para que les ayudasen.

[19] Otrosy, que los dichos ynquisydores dieron por libre e quito a Garçía de Jahén secretario, escrivano de lo crimen de la dicha Çibdad, y dado por quito le privaron de la escrivania de lo crimen, e esto no se puede acabar de entender la cabsa dello dando al señor de la escrivania por libre e quito, e tomarle su ofiçio e darlo a Ginés de Gorvalán, alcaide de los castillos de Jahén por Antonio de Fonseca.

[20] Otrosy, que los dichos ynquisydores por más nos destruyr e destruyr a este linaje absolutamente, como sy fueran señores e fueran suyos estos Reynos, han mandado haser muchos gastos extrahordinarios de nuestras hasyendas, asy en despensero que ponen que nos quita a cada un preso dos mrs. de nuestra casa e manthenimiento, de lo qual, segúnd el número de los presos podia llevar cada un dia quatroçientos mrs., poco más o menos, el qual mantenimiento nos solian llevar de nuestras casas con la propia casa, syn nos tirar mrs. algunos, con lo qual héramos mucho consolados, porque se nos enbiava linpio e bien 
guisado, e asy mismo a la lavandera de los paños de lienço que nos lavava la lavandera puesta por los ynquisydores que se solian lavar e alinpiar en nuestras casas. $E$ en otros alguasyles executores voluntariamente por ellos puestos, demás del alguasyl principal de la dicha Ynquisyçión, y en otros notarios demás de los hordinarios y en otras personas a quienes ellos quieren faser bien de nuestras hasyendas, y en otros gastos extrahordinarios que son en quantya cada un año de más de quatroçientas mill mrs., mandando en esto e en todo tan exarrutamente como sy fuesen señores, en tal manera que sy al preso dan por libre e quito, que a un año o dos o tres que le tienen preso de que sale no falla bieries algunos, asy que quier aprobeche él e su muger e hijos, e sy lo condenan el fisco real de V.A. no falla bienes para su Cámara, porque ya son gastados e destruydos e consumydos.

Los hijos e mugeres e hermanos e parientes de la Vilia de Arjona disen los agravios syguientes, que están en la dicha cárçel de la Ynquisyçión de la C̣ibdad de Jahén:

[1] El comienço e rays de las prisiones fue que un Alvaro de Escalera, vesyno de la dicha villa, se juntó con otros onbres de mal bivir muy henemigos deste linaje y conçertaron todos de enbiar a llamar a los ynquisydores de Jahén con propósito de atestiguar contra ellos, porque fasyéndoles pundonor se venderian sus fasyendas a menos preçio e las conprarian ellos. E fue uno dellos quatro o çinco vezes a llamar los ynquisydores que fuesen Arjona, que avia muchos herejes donde fallarian una mina de oro.

[2] Ydo a la villa un ynquisydor conçertáronse todos aquéllos, proferiéndose el un ynquisydor e a un notario que se llama Bárzena, que fue con él, de aprovecharles en quanto pudiesen, e andovieron de casa en casa por toda la villa, amonestando e provocando a todos los vesynos a mal propósyto disyendo "andad acá, yd todos a testiguar, haremos quemar a los que mataron a Jesuchristo, y quedarnos hemos con sus hasyendas", e a los que no sabian qué desyr les avisaran lo que avian de desyr.

[3] E después, estando el dicho ynquisydor e otros ofiçiales en la dicha villa, pusyeron sus cartas d'edito e fasyanlas leer muchas vezes ante todo el pueblo, el qual hasyan ayuntar en una yglesia para que las leyesen, las quales heran muy escandalosas e abominables de oyr, que segúnd las excomuniones e maldiçiones que ellas estavan [puestas, que hasta] las piedras hasyan mover y tenblar, para yr a testiguar lo que no sabian.

[4] Yten, el dicho ynquisydor enbió a llamar a todos los esclavos y esclavas de los dichos conversos y los halagava y les desya con blandas palabras que dixesen de sus amos por donde los condenasen, e que serian horros e que no oviesen miedo, que ellos lo supiesen e sy de la primera ves que los llamavan no desyan algo, desyanles que se fuesen e se acordasen e que otro dia bolviesen, e asy llamaron a muchos de ellos quatro o çinco vezes, y por ser libres dixeron lo que no sabian.

[5] $Y$ antes que las dichas cartas se leyesen hasyan predicar a un frayle de la horden de Santo Domingo que consygo trayan y predicava cosas para alborotar el pueblo e a los que toviesen buen propósyto fasyanselo mudar en malo para que dixesen lo que no vieron ni oyeron. $Y$ estos escándalos hasyan muchos dias para yndinar la gente, disyendo en los sermones que a los herejes que mataron a Jesuchristo que hera menester cortallos de rays y echallos al fuego. E que no se engañasen, que aunque los veyan yr a misa e a otros ofiçios de la yglesia e faser obras de christianos, que no los creyesen, que todo aquello fasyan por cunplir con la gente, que más judios heran agora aquéstos que los primeros que se tornaron christianos. $Y$ con esto y con otras palabras escandalosas bolvian a la gente para yndinarse contra ellos y faserles desyr que aunque no oviesen visto ninguna cosa fuesen a desyr, o sy por dicha les avian visto desyr o haser algunas cosas a buena parte o con buena yntinçión, como es estar en unos desposorios o otros negoçios como conbites 
muchas gente junta, como lo suelen haser todas las gentes del mundo, fasyéndoles desyr que estavan en ayuntamientos.

[6] Y no contentos con esto, después de averles pedricado y leydo las cartas, cavalgava Bárzena notario y con él otros de aquellos malsynes y un predonero con ellos hasyan pregonar por todas las calles de la dicha villa que todos, asy chicos como grandes, fuesen a desyr para tomalles sus dichos, so pena de dies reales, e qualquier que no fuese asy hijos como moças e mochachas. Y enpadronaron la villa, de casa en casa andavan aquellos malsynes e otros moços de los ynquisydores a monir a todos que pareçiesen delante Su Reverençia, y algunos que no fueron porque no thenian qué desyr les prendaron por los dichos diez reales, entre los quales fueron Gonçalo dÉscañuela e Antón Guijarro e otros muchos.

17] Asy mismo, este dicho Bárzena notario andava por las calles de casa en casa a monir las mugeres e desirles que no hera posyble, pues heran vesynos de los conversos, syno que les verian haser sus heregias, pues que hera çierto que heran herejes, e que no oviesen miedo ni lo dexasen de desyr por vergüença que ninguna cosa de lo que atestiguasen avian de provocar ni se avia de saber quién lo desya, e que todo lo que dixesen avian de provar ellos el contrario y valdria.

[8] Asy mismo, el dicho Bárzena notario, syn mandado del ynquisydor e syn estar él presente tomava los dichos de muchos testigos y enbiava ciédulas con los pregoneros e sacristanes con las quales yvan a llamar e requeryr a todos los vesynos a hecho para que fuesen a desyr sus dichos, so çierta pena. Muchas vezes acaesçe que muchas personas yvan ant el ynquisydor por no caher en la pena, y el dicho ynquisydor les desya "yd a su pasada de Bárzena notario que él os llama», e yvan a ella ant'el dicho Bárzena y les provocava que atestiguasen, y el solo les tomava sus dichos, y los que no querian desyr, amenazávalos diziendo pues no querian desyr de su grado que los llevarian presos a Jahén a su cárçel, donde les harian desyr por fuerça que tenian una malganda lo que él quisiese, e asy lo hisyeron, que llevaron presos a muchos solamente por haserles desyr por fuerça lo que no sabian.

[9] Asy mismo, un Luys de Vilches cantarero, que bivya con el dicho Bárzena, se mudó muchas vezes su nonbre y los vestidos para yr a testiguar. $E$ otras muchas cosas feas pasaron en la dicha villa, e por miedo se dexando pesquisar, espeçialmente el dicho Bárzena notario amenazava a los testigos que al tienpo de ratificar sus dichos desyan que no avian dicho como estava escripto, amenazávalos con la cárçel para que no dixesen otra cosa más de lo que él les leya.

[10] E al tienpo que se fue el dicho ynquisydor de la dicha villa dixo un Lope Gomes, el prinçipal de los malsynes, como se querian yr los padres a Jahén, dixo cmis dineros gastados y los padres ydos y no conversos presos, que tal queda Lope". E asy mismo, éste andava diziendo a Bárzena e a otros "con media dosena de juramentos falsos os puedo ayudar».

[11] E después de aver tomado el ynquisydor las atestiguaçiones, bolviose a Jahén, e for entonçes no prendieron a ninguna persona, y los conversos viendo que no devian [temer] cosa alguna, no se dieron mucho por lo que avia pasado, e asy se pasaron tres meses, fasta que un dia el alguasyl e reçebtor e notarios e otros del ofiçio con ellos vinieron Arjona de noche y en llegando fueron a los regidores e alcaldes de la dicha villa y amonestáronles de nonbre de Dios e del Rey, que por quanto ellos venian a prender los erejes, que a la hora se levantasen secretamente e muniesen gentes e pusiesen guardas en todas las puertas, caños e portillos de la dicha villa, y lo toviesen tomado e a buen recabdo, so çierta protestaçión. E luego, yn continente, se levantaron corregidores [sic] e alcaldes e armaronse e cavalgaron en sus cavallos e fueron a monir gente por la villa, con que antes que amanesçiese estavan las puertas tomadas y adarves con onbres armados e guardas en las torres e por el canpo, e después que fue de día con mucho estruendo e alboroto enpeçaron a prender a los conversos [que] estavan seguros, e todos aquellos malsynes andavan con 
ellos a cavallo favoresciéndoles asy como entravan a qualquier casa a prender, y en prendiendo al marido e a la muger, tomavan ias llaves e echavan a los hijos e moças de casa muy vergosandamente [sic], y echavan a la puerta una herradura, los moços que llevavan apañavan las gallinas e capones que hallavan e otras cosas de comer que llevavan para ellos a sus amos, e asy duró el prender desde dorningo por la mañana fasta el lunes en la noche, que serian los presos fasta quarenta personas. entre omes e mugeres, e pasavan syete e ocho dias e más que no secrestavan las fasyendas e yvan a las casas de los presos e quitavan las herraduras de las puertas y entravan dentro con las llaves y tomavan dinero, plata, oro, aljofar, lienços e lo mejor que avia en la casa e otras cosas de comer que no se asentavan al tienpo del secrestar e no dexavan estar presentes a ninguna de las partes cuya hera la hasyenda syno ellos solos y después le davan a los secrestadores lo que ellos querian.

[12] Asy mismo, después de presos tomaron sus esclavos y esclavas y repartieronlos entre ellos e dexaron a los fijos de los presos solos, porque todas las mas casas prendieron maridos e mugeres, e muchos thenian fijos menudos. que el mayor no se sabe vestir. Metyan petiçiones a los ynquisydores para que los proveyesen de sus esclavos, que los curasen e vistiesen e de lo que a ellos les proveyesen para su mantenimiento darian de comer a los dichos esclavos, syn que ellos les mandasen dar de comer de la hasyenda de sus amos, e no querian, antes se servian dellos e algunos dellos por no ser curados de su mantenimiento como hera de rasón e de ser muy trabajados se han muerto.

[13] Yten, que los dichos ofiçiales echaron en almoneda los esquilmos de los olivares de los presos y otros muchos bienes, que vendian muebles por menudo por menos de lo que valian e rematavanlos luego al primer pregón en quien querian. entre los quales sacaron para sy un olivar de Juan de Córdova e lo traspasaron en Juan de Hojeda porque les dio catorze arrobas de azeyte de ganançia. E. asy mismo, pregonavan los dichos bienes horros de derechos e después de vendidos un recebtor del pronotario de los secrestos cobrava de cada remate çiento e ochenta mrs. de los bienes de los dichos presos seyendo salariado como es.

[14] Yten, la mayor parte de los presos que tienen han seydo syn ynformaçión bastante para los poder prender, $y$ sy algunos ay por ynformaçión fue tomada exarrutamente, pervertyda la horden del derecho no estando presentes los ynquisydores a la examynaçión e retificaçión de los testigos, cometyendo la reçebçión dellos al dicho Bárzena notario, el qual es onbre viçioso e de poca abtoridad e ha cometydo abomynaçiones en su ofiçio terribles.

Humillmente suplicamos a V.A. por serviçio de Dios, nuestro señor, e por los méritos de su santa Pasyón e porque los dichos presos no thenemos culpa, aya por bien V.A. que en nuestras cabsas se proçeda por personas de buenas conçiençias que tengan voluntad de saber e averiguar la verdad, e nos dexe tomar los procuradores e letrados que nosotros e nuestros parientes quisiéremos, e nos oyan de nuevo, pues nunca avemos seydo oydos. $E$ se comuniquen nuestros proçesos con nuestros hijos e parientes, y en esto y en todos los otros articulos proçedan conforme a derecho, y pues el obispo de Jahén es ordinario del dicho obispado e persona de letras e conciencia e de mucha espiriençia en los negocios de la Ynquisyçión y es ynquisydor general por bula apostólica, que V.A. le mande que entienda en las dichas cabsas e haga justicia sobre los dichos agravios e castigue a los culpantes, y en esto deve mandar V.A., pues le consta de la henemistad qu'el arçobispo de Sevilla tyene a todos generalmente antes de la recusaçión e mucho más después, e aunque V.A. le mandó y encargó por una su çedula que sy asy pasava esto de los letrados e procuradores e de no comunicarse los proçesos con nuestros hijos e parientes, que luego 10 remediase e proveyese, e se presentó la çédula al dicho arçobispo e no mandó proveer otra cosa, salvo remutyrme a los ynquisydores por unas palabras generales, los quales. pues ellos han hecho los dichos agravios y por mandamiento e ynstruçiones del dicho ar- 
çobispo, çierta cosa es que no lo remediarán ellos, no se les mandando determinadamente, ni podrian estar en la determinaçión de nuestras cabsas syn mucha pasyón e enemistad. Y en mandar V.A. proveer lo susodicho administrará justiçia e hará limosna e merçed a nosotros e a nuestros hijos e mugeres e parientes. 